\title{
MMP7 Modulation by Short- and Long-term Radiotherapy in Patients with Rectal Cancer
}

\author{
CHRISTINA STENE ${ }^{1}$, ANDREA POLISTENA ${ }^{3}$, ALEXANDER GABER ${ }^{4}$, BJÖRN NODIN $^{4}$, BIANCA OTTOCHIAN $^{2}$, \\ DIYA ADAWI ${ }^{2}$, NICOLA AVENIA ${ }^{3}$, KARIN JIRSTRÖM ${ }^{5}$ and LOUIS BANKA JOHNSON ${ }^{1}$ \\ Divisions of ${ }^{1}$ Colorectal Surgery, ${ }^{2}$ Surgery, and ${ }^{4}$ Pathology, Department of Clinical Sciences, \\ Skåne University Hospital/Malmö, Lund University, Malmö, Sweden; \\ ${ }^{3}$ General and Specialist Surgery Unit, S. Maria University Hospital, Perugia University, Terni, Italy; \\ ${ }^{5}$ Division of Oncology and Pathology, Department of Clinical Sciences, Lund University, Malmö, Sweden
}

\begin{abstract}
Background/Aim: Matrix metalloproteinase 7 (MMP7) expression is highly associated with colorectal cancer and modulates tumour growth and invasion. Radiation injury induces inflammation with increases in MMP7 and in transforming growth factor beta (TGF $\beta)$. The aim of this study was to investigate the effect on MMP7 and TGF $\beta$. expression in patients with rectal cancer undergoing different regimens of neoadjuvant radiotherapy $(R T)$. Patients and Methods: We studied 53 patients in three RT treatment groups receiving $R T$ of $25 \mathrm{~Gy}$, long-term $R T 50$ Gy and controls receiving no $R T$. Three biopsies were obtained from each patient during the treatments: before RT, after RT and after surgery. Tissue samples were formalin fixed, paraffin embedded and tissue microarrays were constructed and stained for MMP7 and TGF $\beta$. Mann-Whitney U-tests and Wilcoxon Z-tests were used to determine differences between patients before and after RT, and after surgery, as well as between the RT groups. Results: In all three patient groups, increases of MMP7 and TGF $\beta$ expression were observed after surgery. MMP7 expression was significantly increased in patients receiving short-term RT but TGF $\beta$ expression was not affected by RT. Conclusion: 50 Gy Irradiation of rectal cancer gives less tumour activation of MMP7, whilst it is upregulated by 25 Gy and surgery regardless of $R T$.
\end{abstract}

This article is freely accessible online.

Correspondence to: Louis Banka Johnson, MD, Ph.D., Department of Clinical Sciences, Division of Colorectal Surgery \& Pelvic Floor Centre, Skåne University Hospital/Malmö, Lund University, Jan Waldenströms gata 11 A, 20502 Malmö, Sweden. Tel: +46 40336557, Fax: +46 40337877, e-mail: louis.johnson@med.lu.se

Key Words: Matrilysin, matrix metalloproteinases, rectal cancer, radiotherapy, inflammation.
Colorectal cancer is the third most common malignancy in the world, thus constituting the most frequent reason for gastrointestinal resection (1). In Sweden in 2009, 5,755 persons were diagnosed with colorectal cancer, of whom 2,144 had rectal cancer. Approximately $70 \%$ of patients with rectal cancer underwent surgical resection of their tumour (2).

Neoadjuvant radiotherapy (RT) is used in more than $60 \%$ of Swedish patients with the intention of either reducing local recurrence by improved local control or downsizing of tumours that primarily are not resectable. Preoperative short term RT of $5 \times 5$ Gy for 1 week followed by surgery within 3 days has been increasingly used as a treatment for patients with resectable rectal cancer. Long-term RT, consisting of $28 \times 1.8$ Gy for 5 weeks followed by surgery after 6-8 weeks, is used preoperatively to downsize tumours originally diagnosed as locally advanced.

The use of preoperative RT in rectal cancer treatment has resulted in a decreased rate of local recurrences and increased survival rate (3). However, pelvic RT is frequently associated with morbidity in the short as well as in the long term. A plethora of complications, including delayed wound healing, perineal wound infection, postoperative abscess, fistula, intestinal obstruction, perforation and bleeding, are described with negative effects on functional outcome such as diarrhoea, urgency and faecal incontinence (4).

Irradiation of intestinal mucosa may cause alteration or reduction of gut microbiota, leading to an unfavourable growth of opportunistic microorganisms. This process is thought to enhance mucosal damage and intestinal inflammation related to gut RT (5-8).

Matrix metalloproteinases (MMPs) are endopeptidases belonging to a family of zinc-dependent enzymes with proteolytic properties capable of degrading all components of both the basement membrane and the extracellular matrix (ECM). This property has been suggested to be of importance in enabling tumour cells to invade and spread $(9,10)$. 
MMPs are induced by interactions not only between cells and the ECM but also by cytokines and growth factors. The ECM is remodelled by ionizing radiation which causes extensive oxidative damage at the cellular level and of numerous enzymes, for example the multifunctional inflammatory cytokine transforming growth factor beta (TGF $\beta$ ) and MMPs (9).

Malignant epithelial cells are unique in expressing matrix metalloproteinase 7 (MMP7), known as matrilysin, a protease that increases in metastatic colorectal cancer (9). In a murine model of radiation-induced enteropathy, both MMP7 and TGF $\beta$ were up-regulated by irradiation (11). RT has also been found to induce an elevation of MMP7 in humans $(9,12)$. During wound healing, activation of MMPs is required in several of the steps leading to restoration of tissue integrity.

The aim of this prospective study was to investigate if different RT regimens with standard surgical treatment affect MMP7 and TGF $\beta$ expression in patients with rectal cancer.

\section{Patients and Methods}

Patients. This study was a prospective descriptive study where originally 77 patients diagnosed with rectal cancer were treated at Skåne University Hospital in Malmö, Sweden, between 2004 and 2007. All patients were managed according to the clinical protocol of the Department of Clinical Sciences, Division of Colorectal Surgery, adhering to national guidelines and assessment of the local multidisciplinary treatment board. A total of 24 patients were excluded from the study due to revised pathological diagnosis showing high-grade dysplasia (eight patients), impaired general condition (eight patients), declining to participate (four patients), synchronous colonic tumours (three patients) and for logistical reasons in one patient, with the final cohort therefore comprising 53 patients. Seventeen patients were female $(32.1 \%)$ and 36 were male $(67.9 \%)$. The study was approved by the Ethics Committee at Lund University, Sweden (ref 144/2004, amendment 597/2006) and registered at Clinical Trials, ID NCT03151759. Written consent was obtained from each patient after provision of oral and written information. Staging was performed according to the TNM system (13). Exclusion criteria included previous RT to the pelvic region, inflammatory bowel disease, neoadjuvant chemotherapy, as well as ongoing steroid, immunosuppressive or antibiotic therapy.

Three treatment groups were defined: one group received shortterm preoperative RT of 25 Gy ( $5 \times 5$ Gy) followed by surgery, 20 patients; another group was treated with long-term preoperative RT of $50 \mathrm{~Gy}(28 \times 1.8 \mathrm{~Gy})$ followed by surgery, 21 patients; and a control group underwent surgery alone without RT, 12 patients.

Surgical procedures performed were either anterior resection or abdominoperineal resection, by the total mesorectal excision technique. A rigid rectosigmoidoscopy was performed before and after irradiation/before start of surgery. Two-millimeter punch biopsies were obtained from tumour tissue within the irradiated field. Samples were taken on three occasions: at inclusion before RT; after RT prior to start of surgery to eliminate possible effects of surgical trauma and ischaemia on MMP expression; and from the excised specimen. All tissue samples were instantly formalin fixed and paraffin embedded.
Tissue microarrays. Tissue microarray (TMA) was performed in two series: one TMA with $1 \times 1 \mathrm{~mm}$ cores taken from biopsies of tumour tissue, and one TMA from the complete surgical specimens through which $2 \times 1 \mathrm{~mm}$ cores were drawn from areas comprising tumour. This was performed using a manual arraying device (MTA-1; Beecher Inc., Sun Prairie, WI, USA) and tissue samples were mounted in a recipient block.

Immunohistochemistry and staining evaluation. The TMAs were cut into $4-\mu \mathrm{m}$ sections pretreated in a DAKO PT-link module using a standard protocol and buffer supplied by the manufacturer (DAKO, Glostrup, Denmark). Thereafter slides were stained in a DAKO Autostainer-plus using the EnVision ${ }^{\mathrm{TM}}$ FLEX including PeroxidiseBlocking Reagent (DAKO) with mouse monoclonal antibody to MMP7 (dilution 1:50; Santa Cruz, Dallas, TX, USA and rabbit polyclonal antibody to TGF $\beta$ (dilution 1:200; Abcam, Cambridge, UK). Immunohistochemistry was performed by an automated staining machine (Ventana Medical Systems, Inc., Tucson, AZ, USA).

Three research scientists jointly annotated cytoplasmic expression of MMP7 and TGF $\beta$ in tumour tissue for each core. Annotation of the absolute percentage of positively stained cells was multiplied by the annotated intensity (scored 0-3) of stained cells, and a mean expression score was subsequently calculated for each patient at each time point. This method was validated earlier (1416). Discrepant cores were discussed until consensus was reached.

Statistical analysis. Spearman's Rho and chi-squared tests were used to investigate RT groups and patient characteristics (Table I). MannWhitney $U$-test/Wilcoxon Z-test were used to investigate differences in MMP7 expression between tissue before and after radiotherapy, and after surgery, in the RT subgroups, as well as for the TGF $\beta$ analysis. Fishers exact test was used in single case analyses. All statistical analyses were performed using SPSS ver.21.0 (IBM Corp., Armonk, NY, USA); associations/differences with $p$-values of less than 0.05 were considered significant.

\section{Results}

The majority of patients in the different groups were male and younger than 75 years. Disease stages were equally distributed among groups with the exception of stage IV, with a very low number of cases enrolled (Table I).

For the whole cohort, no significant increase of MMP7 or TGF $\beta$ was observed after RT, whereas after surgery, MMP7 expression was significantly increased $(p<0.001, Z=-6.167)$ as was that of TFG $\beta(p<0.001, Z=-6.651)$ (Figure 1).

In patients treated with short-term RT, MMP7 showed a borderline significant increase after RT compared to baseline (Fishers' $p=0.065$, two-tail $p=0.025, \mathrm{Z}=-2.230$ ), and a significant rise after surgery (Fishers' $p<0.001, Z=-4.147$ ) compared to baseline (Table II). TGF $\beta$ was not significantly affected by RT but also significantly increased after surgery (Fishers' $p<0.001, \mathrm{Z}=-4.010$ ) (Table III).

In the group treated with long-term RT, both MMP7 and TGF $\beta$ were unaffected by RT but increased after surgery (MMP7: Fishers' $p=0.005, \mathrm{Z}=-2.870$; TGF $\beta$ : Fishers' $p<0.001, \mathrm{Z}=-3.862)$. 
Table I. Patient characteristics.

\begin{tabular}{|c|c|c|c|c|}
\hline & \multicolumn{3}{|c|}{ RT before surgery, n (\%) } & \multirow[b]{2}{*}{$p$-Value } \\
\hline & None & $\begin{array}{l}\text { Short } \\
\text {-term }\end{array}$ & $\begin{array}{l}\text { Long- } \\
\text { term }\end{array}$ & \\
\hline \multicolumn{5}{|l|}{ Characteristic } \\
\hline Total, $\mathrm{n}$ & $12(22.6)$ & $20(37.8)$ & $21(39.6)$ & \\
\hline \multicolumn{5}{|c|}{ 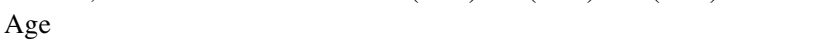 } \\
\hline$<75$ Years & $8(66.7)$ & $15(75.0)$ & $16(76.2)$ & \\
\hline$\geq 75$ Years & $4(33.3)$ & $5(25.0)$ & $5(23.8)$ & 0.823 \\
\hline \multicolumn{5}{|l|}{ Gender } \\
\hline Male & $9(75.0)$ & $14(70.0)$ & $13(61.9)$ & \\
\hline Female & $3(25.0)$ & $6(30.0)$ & $8(38.1)$ & 0.717 \\
\hline \multicolumn{5}{|l|}{ Clinical staging } \\
\hline I & $2(16.7)$ & $2(10.0)$ & $0(0)$ & \\
\hline II & $9(75.0)$ & $8(40.0)$ & $6(28.6)$ & \\
\hline III & $0(0)$ & $10(50.0)$ & $15(71.4)$ & \\
\hline IV & $1(8.3)$ & $0(0)$ & $0(0)$ & \\
\hline Missing & $0(0)$ & $0(0)$ & $0(0)$ & 0.005 \\
\hline \multicolumn{5}{|l|}{ Pathological staging } \\
\hline I & $3(25.0)$ & $7(35.0)$ & $4(19.0)$ & \\
\hline II & $4(33.3)$ & $3(15.0)$ & $7(33.3)$ & \\
\hline III & $4(33.3)$ & $8(40.0)$ & $7(33.3)$ & \\
\hline IV & $1(8.3)$ & $2(10.0)$ & $1(4.8)$ & \\
\hline Missing & $0(0)$ & $0(0)$ & $2(9.5)$ & 0.628 \\
\hline \multicolumn{5}{|l|}{ Operative procedure } \\
\hline Anterior resection & $9(75.0)$ & $11(55.0)$ & $9(42.9)$ & \\
\hline Abdomino-perineal resection & $2(16.7)$ & $8(40.0)$ & $8(38.1)$ & \\
\hline Hartmann & $1(8.3)$ & $1(5.0)$ & $3(14.3)$ & \\
\hline Missing & $0(0)$ & $0(0)$ & $1(4.8)$ & 0.506 \\
\hline
\end{tabular}

Expression in patients not treated with RT exhibited a similar trend, with increased MMP7 and TGF $\beta$ expression after surgery (MMP7: Fishers' $p=0.002, Z=-3.208$; TGF $\beta$ : Fishers' $p<0.001, \mathrm{Z}=-3.399)$.

\section{Discussion}

The expression of $M M P 7$ m-RNA in humans is highly specific for malignant epithelial cells of colorectal cancer, with it being only weakly expressed in normal colorectal mucosa, with a progressive trend from normal mucosa to cancer. Varied expressions with increasing grade of dysplasia and inflammation have been observed $(9,17-19)$. In cancer immunology, a clear role of MMP7 and of other MMPs has been shown in tumour growth and invasion $(17,20-25)$. Increased MMP7 expression in tumour tissue, serum, lymph nodes and peritoneal liquid generally correlates with worse prognosis, a tendency for metastatic disease and reduced overall survival $(18,26-32)$. This suggests a possible role for MMP7 in the determination of locally advanced cancer in resected specimens, and in staging and planning for eventual adjuvant therapy, attesting to a potential role of MMP7 as prognostic factor and tumour marker (33).
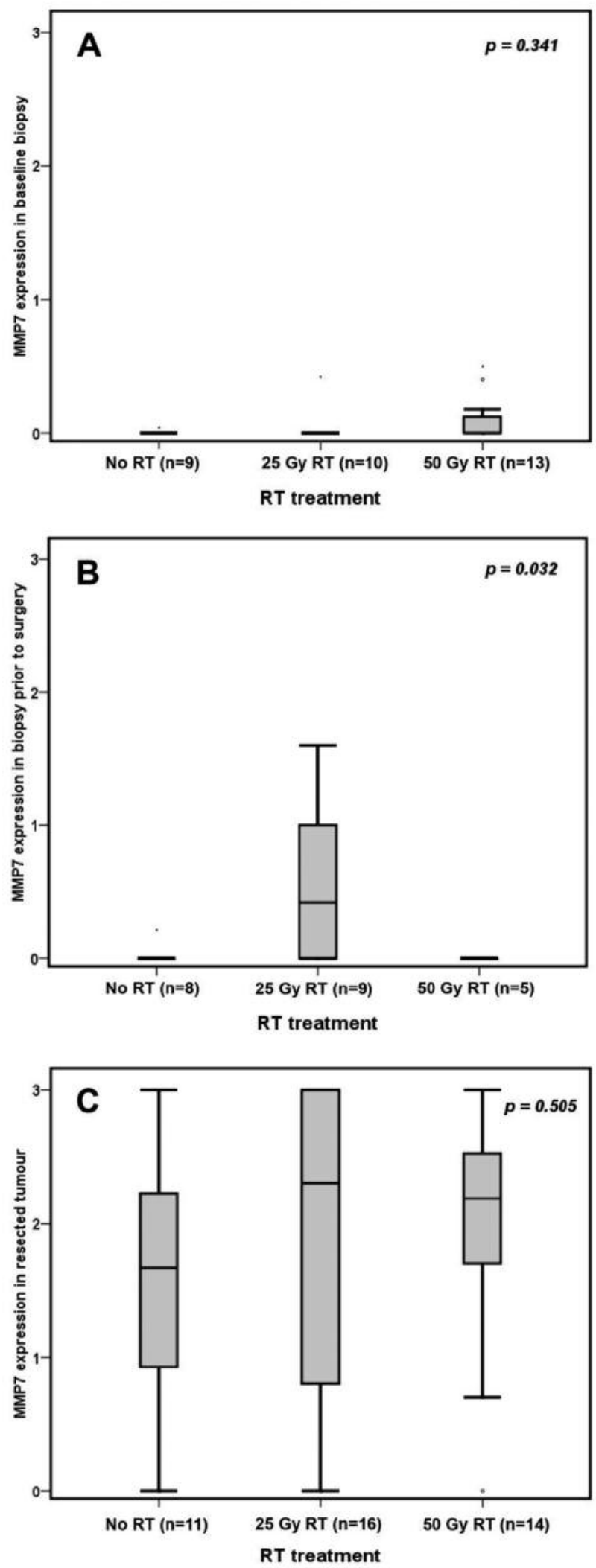

Figure 1. Matrix metalloproteinase 7 (MMP7) expression in the two radiotherapy $(R T)$ regimen and in controls, in the baseline. 
in vivo $32: 133-138(2018)$

Table II. Tumour expression of matrix metalloproteinase 7 (MMP7) before and after treatment. Mean rank is used to approximate relation between the MMP7 at treatment times.

\begin{tabular}{|c|c|c|c|c|c|}
\hline Group & Time point & $\mathrm{n}$ & MMP7 mean rank & $p$-Value* & Z-value* \\
\hline \multirow[t]{3}{*}{ Long-term RT } & Baseline & 10 & 8.05 & & \\
\hline & Before surgery & 9 & 16.56 & 0.065 & -2.230 \\
\hline & After surgery & 16 & 25.03 & $<0.00001$ & -4.147 \\
\hline \multirow[t]{3}{*}{ Short-term RT } & Baseline & 13 & 12.92 & & \\
\hline & Before surgery & 5 & 9.00 & 0.336 & -1.353 \\
\hline & After surgery & 14 & 22.50 & 0.005 & -2.870 \\
\hline \multirow[t]{3}{*}{ No RT } & Baseline & 9 & 10.00 & & \\
\hline & Before surgery & 8 & 10.25 & 0.963 & -0.172 \\
\hline & After surgery & 11 & 21.27 & 0.0016 & -3.208 \\
\hline
\end{tabular}

RT: Radiotherapy. *Compared to baseline.

The effect of RT on MMP7 gene in human rectal cancer was first investigated in vivo by Kumar et al., who observed overexpression of MMP7 in radiated rectal cancer tissue compared to nearby irradiated normal rectal tissue (9). Due to the strict correlation between surgery and RT in the current multimodal management of rectal cancer, the effect and the consequent possible modulation of radiation-induced MMP7 overexpression remains a current field of investigation which is still far from complete due to its complex features and to the several molecules and pathways involved.

The expression of MMP7 and of other MMPs is usually the result of specific immunological stimuli due to physiological and pathological processes leading to proliferation and remodelling in tissue growth and differentiation. This is seen in tissue repair and wound healing after inflammation, and after various types of injury and trauma (11, 34-36). In our clinical setting, there was a double factor potentially acting on ECM remodelling since RT alone or surgery alone, or both in combination, clearly affected MMP7 expression. Control cases (no RT) presented significantly higher expression only after surgical resection. In cases irradiated with $50 \mathrm{~Gy}$, the effect of RT itself seemed not to influence MMP7 expression, however, there was a tendency for radiation to reduce MMP7 expression, probably reflecting less radiation injury of the tissue. Only after surgery did these irradiated patients present significantly higher expression of MMP7 comparable to that of the the 25 Gy RT group, which after RT alone already had a significant increase in MMP7 expression before surgery. Expression significantly further increased after surgery. The analysis of these results demonstrated that MMP7 is overexpressed after different types of stimulation. Surgery alone was effective in inducing up-regulation and, in combination with short-term (25 Gy) RT, led to a further overexpression of MMP7 after RT. Higher doses of RT (50 Gy) with surgery delayed by more than a month did not lead
Table III. Tumour expression of transforming growth factor beta (TGF $\beta$ ) before and after treatment compared to baseline.

\begin{tabular}{lcccc}
\hline Group & $\mathrm{n}$ & TGF $\beta$ mean rank & $p$-Value & Z-value \\
\hline 25 Gy RT & & & & \\
Baseline & 9 & 7.72 & & \\
Before surgery & 6 & 9.17 & 0.529 & -0.714 \\
After surgery & 18 & 24.25 & $<0.0001$ & -4.010 \\
50 Gy RT & & & & \\
Baseline & 10 & 6.95 & & \\
Before surgery & 2 & 8.00 & 1.000 & 0.000 \\
After surgery & 14 & 18.96 & $<0.0001$ & -3.862 \\
No RT & & & & \\
Baseline & 8 & 8.12 & & \\
Before surgery & 5 & 5.80 & 0.435 & -0.897 \\
After surgery & 11 & 18.73 & 0.0002 & -3.399 \\
\hline
\end{tabular}

to any increases in MMP7 at the time of surgery compared to level observed at baseline. The explanation here might be ascribed to the waiting time after sample collection since according to the neoadjuvant protocol, patients underwent surgery 6-8 weeks after completion of RT, which is sufficient time for the effects of induced overexpression to be lost. Our results for the $50 \mathrm{~Gy}$-treated group, however, may be biased by the low number of patients that it was possible to adequately examine and analyze. This was due to the fragility and poor staining of the specimens from such patients, whereby only five cases were accepted for examination. Given the role of MMP7 in abnormal tissue remodelling after RT injury $(9,25,29)$ and its relation to progressive and metastatic colorectal disease, it may be rational to use potential preventive or therapeutic specific tissue inhibitors of MMPs with RT.

Surgical trauma was seen to affect MMP7 expression in all the examined groups. Our observation of the marked 
differences in the two RT regimes may support usage of the more favourable long course treatment, due to its limited effect on MMP7 expression, and consequently on reduced tumour progression. Members of our group have earlier shown the progressive expression of MMP7 from normal mucosa to cancer; MMP7 levels were up to 10 -fold lower in normal mucosa compared to those in tumour samples $(9,17,18)$.

A homogenous trend was observed in the expression of TGF $\beta$, as a marker of inflammation and fibrosis, in tumour before and after treatment compared to baseline. In the three groups, no significant increase of TGF $\beta$ was observed after 25 and 50 Gy RT immediately before surgery. However, TGF $\beta$ increased significantly, 2- to 3-fold only after surgery, with maximum increase in the $25 \mathrm{~Gy}$ irradiated group. TGF $\beta$ participates in the remodelling of the ECM, but has many other functions, such as suppression of the immune system and regulation of cell growth. It was also shown to act both as an inhibitor of tumour growth and as a promoter of tumour progression $(37,38)$.

TGF $\beta$ activated by radiation may be involved in the mechanisms of increased inflammation after RT eventually leading to fibrosis (39). A previous investigation from our group in fact showed that RT and surgery induced depression of TGF $\beta$ in rats in the first postoperative week followed by up-regulation in the late period $(38,40)$. Similarly, other authors showed lower levels of active TGF $\beta$ in both tumour tissue and rectal mucosa in patients irradiated for rectal cancer (38). Evidence points towards RT-induced activation of latent TGF $\beta$ but this activation may only be seen in a limited time window, which may not have been captured in these studies.

In conclusion, we can state that surgery has an overriding effect on the up-regulation of MMP7 and the inflammatory cytokine TGF $\beta$. In our clinical setting, preoperative RT of 50 Gy induced significantly less MMP7 expression at surgery compared to short-term irradiation of $25 \mathrm{~Gy}$. This difference supports usage of the more favourable long course treatment, for its limited effect on MMP7 expression and consequently on reducing tumor progression.

Although there is a wide body of literature available dealing mainly with short-term RT, to our knowledge there are no previous publications comparing the effects of short-and long-course RT on MMP7 expression in patients with rectal cancer. For this reason, the present study must be considered a pilot investigation on the modulation of expression by different RT courses in this setting. The main limitation of the present research was the low number of patients enrolled in the different groups. Further studies are needed to validate these findings and to better understand the pathways involved in progressive cancer disease through ECM remodelling under the influence of RT.

\section{Acknowledgements}

This work was supported by grants from Malmö University Hospital Cancer Foundation and Einar \& Inga Nilsson's Foundation. The Authors thank Research Nurse Ingrid Palmquist for invaluable help with coordination of the patients.

\section{References}

1 Parkin D M, Bray F, Ferlay J and Pisani P: Global cancer statistics. CA Cancer J Clinic 55: 74-108, 2002.

2 Swedish Colorectal Cancer Registry: www.cancercentrum.se

3 Lidder PG and Hosie KB: Rectal cancer: the role of radiotherapy. Dig Surg 22: 41-49, 2005.

4 Parc Y, Zutshi M, Zalinski S, Ruppert R, Fürst A and Fazio VW: Preoperative radiotherapy is associated with worse functional results after coloanal anastomosis for rectal cancer. Dis Colon Rectum 52: 2004-2014, 2009.

5 Ouwehand AC, Tölkkö S, Kulmala J, Salminen S and Salminen E: Adhesion of inactivated probiotic strains to intestinal mucus. Lett Appl Microbiol 31: 82-86, 2000.

6 Korschunov VM, Smeianov VV, Efimov BA, Tarabrina NP, Ivanov AA and Baranov AE: Therapeutic use of an antibioticresistant Bifidobacterium preparation in men exposed to highdose gamma-irradiation. J Med Microbiol 44: 70-74, 1996.

7 Benová K, Falis M, Toropila M, Sehnalková H and Pastvová L: Influence of a single gamma-irradiation on rat microflora. Folia Microbiol 47: 461-462, 2002.

8 Johnson LB, Riaz AA, Adawi D, Wittgren L, Bäck S, Thornberg C, Osman N, Gadaleanu V, Thorlacius H and Jeppsson B: Radiation enteropathy and leucocyte-endothelial cell reactions in a refined small bowel model. BMC Surg 4: 10, 2004.

9 Kumar A, Collins H, Van Tam J, Scholefield JH and Watson SA: Effect of preoperative radiotherapy on matrilysin gene expression in rectal cancer. Eur J Cancer 38: 505-510, 2002.

10 Florczak-Rzepka M, Grond-Ginsbach C, Montaner J and Steiner T: Matrix metalloproteinases in human spontaneous intracerebral hemorrhage: an update. Cerebrovasc Dis 34: 249-262, 2012.

11 Polistena A, Johnson LB, Röme A Wittgren L, Bäck S, Osman N, Molin G, Adawi D and Jeppsson B: Matrilysin expression related to radiation and microflora changes in murine bowel. $\mathrm{J}$ Surg Res 167: e137-143, 2011.

12 Birgisson H, Påhlman L, Gunnarsson U and Glimelius B: Late gastrointestinal disorders after rectal cancer surgery with and without preoperative radiation therapy. Br J Surg 95: 206-213, 2008.

13 American Joint Committee on Cancer, AJCC. Cancer Staging Manual Sixth Edition. Springer, pp. 113-123, 2002.

14 Bergenfelz C, Gaber A, Allaoui R, Mehmeti M, Jirström K, Leanderson $\mathrm{T}$ and Leandersson K: S100A9 expressed in $\mathrm{ER}(-) \operatorname{PgR}(-)$ breast cancers induces inflammatory cytokines and is associated with an impaired overall survival. In: Br J Cancer 113: 1234-1243, 2015.

15 Jonsson L, Hedner C, Gaber A, Korkocic D, Nodin B, Uhlén M, Eberhard $\mathrm{J}$ and Jirström K: High expression of RNA-binding motif protein 3 in esophageal and gastric adenocarcinoma correlates with intestinal metaplasia-associated tumours and independently predicts a reduced risk of recurrence and death. Biomark Res 2: 11, 2014. 
16 Hedner C, Gaber A, Korkocic D, Nodin B, Uhlén M, Kuteeva E, Johannesson H, Jirström K and Eberhard J: SATB1 is an independent prognostic factor in radically resected upper gastrointestinal tract adenocarcinoma. Virchows Arch 465: 649459,2014

17 Ishikawa T, Ichikawa Y, Mitsuhashi M, Momiyama N, Chishima T, Tanaka K, Yamaoka H, Miyazakic K, Nagashima Y, Akitaya $\mathrm{T}$ and Shimada H: Matrilysin is associated with progression of colorectal tumor. Cancer Lett 107: 5-10, 1996.

18 Polistena A, Cucina A, Dinicola S, Stene C, Cavallaro G, Ciardi A, Orlando G, Arena R, D'Ermo G, Cavallaro A, Johnson LB and De Toma G: MMP7 expression in colorectal tumours of different stages. In Vivo 28: 105-110, 2014.

19 Newell KJ, Matrisian LM and Driman DK: Matrilysin (matrix metalloproteinase-7) expression in ulcerative colitis-related tumorigenesis. Mol Carcinog 34: 59-63, 2002.

20 Declerck YA, Perez N, Shimada H, Boone TC, Langley KE and Taylor SM: Inhibition of invasion and metastasis in cells transfected with an inhibitor of metalloproteinase. Cancer Res 52: 701-708, 1992.

21 Mori M, Barnard GF, Mimori K, Ueo H, Akiyoshi T and Sugimachi K: Overexpression of matrix metalloproteinase-7 mRNA in human colon carcinomas. Cancer 75: 1516-1519, 1995.

22 Roeb E, Dietrich CG, Winograd R, Arndt M, Breuer B, Fass J, Schumpelick V and Matern S: Activity and cellular origin of gelatinases in patients with colon and rectal carcinoma. Differential activity of matrix metalloproteinase-9. Cancer 92: 2680-2691, 2001

23 Masaki T, Matsuoka H, Sugiyama M, Abe N, Goto A, Sakamoto A and Atomi Y: Matrilisyn (MMP7) as significant determinant of malignant potential of early invasive colorectal carcinomas. Br J Cancer 84: 1317-1321, 2001.

24. Kitamura T, Biyajima K, Masahiro A, Oshima M and Taketo MM: Matrix metalloproteinase 7 is required for tumor formation, but dispensable for invasion and fibrosis in SMAD4-deficient intestinal adenocarcinomas. Lab Invest 89: 98-105, 2009.

25 Waas ET, Lomme RM, DeGroot J, Wobbes T and Hendrikis T: Tissue levels of active metalloproteinase- 2 and 9 in colorectal cancer. Br J Cancer 17: 1876-1883, 2002.

26 Fuksiewicz M, Kotowicz B, Rutkowski A and Kowalska M: The matrix metalloproteinase-7 and pro-enzyme of metalloproteinase1 as a potential marker for patients with rectal cancer without distant metastasis. Tumour Biol 36: 3629-3635, 2015.

27 Sun DW, Zhang YY, Qi Y, Zhou XT and Lu GY: Prognostic significance of MMP7 expression in colorectal cancer: a metaanalysis. Cancer Epidemiol 39: 135-142, 2015.

28 Sica GS, Fiorani C, Stolfi C, Monteleone G, Candi E, Amelio I, Catani V, Sibio S, Divizia A, Tema G, Iaculli E and Gaspari AL: Peritoneal expression of matrilysin helps identify early postoperative recurrence of colorectal cancer. Oncotarget 30: 1340213415, 2015.

29 Martinez-Fernandez A, Garcia Albeniz X, Pineda E Visa L, Gallego R, Codony-Servat J, Augé JM, Longarón R, Gascón P, Lacy A, Castells A and Maurel J: Serum matrilysin levels predict outcome in curatively resected colorectal cancer patients. Ann Surg Oncol 16: 1412-1420, 2009.
30 Lloyd JM, Mclver CM, Stephenson SA, Hewett PJ, Rieger N and Hardingham JE: Identification of early-stage colorectal cancer patients at risk of relapse post-resection by immunobead reverse transcription-PCR analysis of peritoneal lavage fluid for malignant cells. Clin Cancer Res 12: 417-423, 2006.

31 Ishida H, Murata N, Tada M, Okada N, Hashimoto D, Kubota S, Shirakawa K and Wakasugi H: Determining the levels of metalloproteinase-9 in portal and peripheral blood is useful for predicting liver metastasis of colorectal cancer. Jpn J Clin Oncol 33: 186-191, 2003.

32 Ichikawa Y, Ishikawa T, Momiyama N, Yamaguchi S, Masui H, Hasegawa S, Chishima T, Takimoto A, Kitamura H, Akitaya T, Hosokawa T, Mitsuhashi $\mathrm{M}$ and Shimada $\mathrm{H}$ : Detection of regional lymph node metastases in colon cancer by using RTPCR for matrix metalloproteinase 7, matrilysin. Clin Exp Metastasis 16: 3-8, 1998.

33 Chen H, Hu Y, Xiang W, Cai Y, Wang Z, Xiao Q, Liu Y, Li Q and Ding K: Prognostic significance of matrix metalloproteinase 7 immunohistochemical expression in colorectal cancer: a metaanalysis. Int J Clin Exp Med 8: 3281-3290, 2015.

34 Parks WC, Lopez-BoadoYS and Wilson CL: Matrilysin in epithelial repair and defense. Chest 120: 36s-41s, 2001.

35 Wilson CL, Heppner KJ, Rudolph LA and Matrisian LM: The metalloproteinase matrilysin is preferentially expressed by epithelial cells in a tissue-restricted pattern in the mouse. Mol Biol Cell 6: 851-869, 1995.

36 Lopez-Boado YS, Wilson CL, Hooper LV, Gordon JI, Hultgren SJ and Parks WC: Bacterial exposure induces and activates matrilysin in mucosal epithelial cells. J Cell Biol 148: 13051315,2000

37 Polistena A, Johnson LB, Ohiami-Masseron S, Wittgren L, Bäck S, Thornberg C, Gadaleanu V, Adawi D and Jeppsson B: Local radiotherapy of exposed murine small bowel: apoptosis and inflammation. BMC Surg 8: 1, 2008.

38 Angenete E, Langenskiold M, Palmgren I, Falk P, Oresland T and Ivarsson ML: Transforming growth factor beta-1 in rectal tumour mucosa and plasma in relation to radiotherapy and clinical outcome in rectal cancer patients. Int J Colorectal Dis 22: 1331-1338, 2007.

39 Bentzen SM: Preventing or reducing late side-effects of radiation therapy: Radiobiology meets molecular pathology. Nat Rev Cancer 6: 702-713, 2006.

40 Johnson LB, Adawi D, Agren MS, Jorgensen LN, Wittgren L, Mattsson S, Blomquist P, Gottrup F and Jeppsson B: Combination of pre-operative radiotherapy and surgery suppresses local accumulation of collagen and TGF-beta1 in rats. J Surg Res 133: 136-142, 2006. 